\title{
THE PRINCIPLE OF CONSTRUCTING THE ALGORITHM OF THE FUNCTIONING OF THE NEURAL NETWORK - THE BASIS OF THE EXAM SYSTEM OF ARTIFICIAL INTELLIGENCE
}

\author{
Ibragim Suleimenov ${ }^{1, *}$, \\ Alimzhan Baykenov ${ }^{1}$, \\ Tolganay Abisheva ${ }^{1}$, \\ llyas Kopishev ${ }^{2}$
}

${ }^{1}$ Almaty University of Power Engineering and Telecommunications, Almaty, Kazakhstan ${ }^{2}$ S. Toraighirov Pavlodar State University, Pavlodar, Kazakhstan

\begin{abstract}
:
A new approach to the development of artificial intelligence systems aimed at improving the quality of higher education in post-Soviet countries has been proposed and substantiated. The purpose of the system is to set examination marks in an automated mode based on the student's ability to assimilate new scientific and technical information for him (reading and subsequent retelling of the text). This approach is designed to ensure a reduction in the level of corruption in post-Soviet universities, the scale of which already poses a real threat to the intellectual sovereignty of the post-Soviet states.
\end{abstract}

\section{Keywords:}

corruption, higher education, artificial intelligence, neural networks, examination marks.

\section{INTRODUCTION}

Prospects for the use of artificial intelligence systems (AI) in the educational process are actively discussed in the current literature [1][3]. In particular, the possibilities of using AI as an instrument to combat the bureaucratization of the educational process and corruption in higher education are being analyzed [4], [5].

In many post-Soviet states, including in Kazakhstan, the scope of corruption in universities has de facto reached a level at which there is a question about its impact on national security [4], [5], although the authors of most of the works on this subject speak with some a touch of "bashfulness", accompanying their judgments with various reservations [6]-[9].

The existing scale of corruption, flourishing in universities, really represents a direct threat to the geopolitical level, since a significant reduction in the quality of higher education associated with corruption manifestations already calls into question both the intellectual sovereignty of the post-Soviet states and their ability to ensure the development of promising technologies, including including in the military-technical sphere [4], [5]. However, it should be noted that the issue of corruption in universities is actively discussed in the world literature [10]-[12], and the growth in the number of publications on this topic is indicative (Figure 1). 
Proceeding from this, as well as from the basic provisions of the strategy for the development of AI systems in the Republic of Kazakhstan, built on the principles of ensuring the intellectual sovereignty of the country [13], for countries such as Kazakhstan, when developing an AI system, they should first of all be considered as a promising means of fighting corruption in universities.

In this paper, we propose an algorithm for the functioning of the neural network, the basis of the AI system, which provides for counteracting corruption in exams by damping the human factor in grading. It is obvious that in modern conditions it is the evaluation of a student's knowledge that maximizes the subjective factor, which, among other things, creates a fertile ground for corruption. Therefore, the development of any means to maximally eliminate or dampen the human factor in grading can be considered, including as a means of countering corruption.

The basic idea of this algorithm is as follows. As it was emphasized in [14], the modern conditions make no sense to try to assess the student's intellectual potential based on the amount of knowledge that he currently has. In favor of this consideration, in particular, the following circumstance. In the vast majority of areas of modern science has accumulated more than a significant amount of information. Accordingly, the formation of curricula becomes an extremely complex process, since it is required to isolate the information that forms the basis of this particular profession. The selection of this information is a very nontrivial task, for the solution of which various approaches are proposed [4]. However, this question remains essentially controversial, since it is still unclear on which particular principles the above mentioned selection should be made.

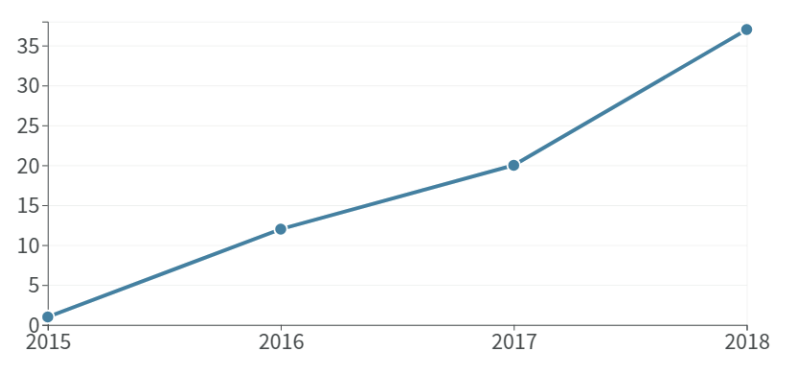

Fig. 1. Dynamics of growth in the number of publications devoted to the discussion of corruption in higher education, according to the database Web of Science (search by keyword "Corruption" and "higher education")
Currently, the method of expert assessments is used de facto, that is, each specific university compiles a curriculum based on its own capabilities and points of view of the faculty on the maintenance and further development of a particular discipline. As a result the content of the curricula of the overwhelming majority of post-Soviet universities in each particular discipline is de facto random. (The determining factor here, obviously, is the area of their scientific interests of specific teachers and the amount of knowledge that they possess.) However, the non-systemic nature of the formation of curricula is not a determining obstacle to the formation of a modern specialist. It is especially true in relation to the field of information technology.

Indeed, in the overwhelming majority of cases at particular workplaces, university graduates do not use the specific information that they received during their university studies. (This is especially clearly shown by the fact that more than half of university graduates from post-Soviet countries do not work in their specialty.) Accordingly, the main result of university studies (the main professional skill) in modern conditions is, de facto, the student's ability to absorb new information.

The presence of basic knowledge, in the first place, determines precisely this skill, which becomes the base for a specialist of any qualification. It is important to have a certain set of basic knowledge that will further allow us to adequately assimilate new information (for example, the information contained in the descriptions of technical systems or the information contained in highly specialized scientific and technical works).

Based on this, in modern conditions, at least for students in the last undergraduate courses or students in the magistracy, it is advisable to use an approach based on the assessment of the student to process and assimilate new information. Schematically, is illustrated in Figure 2.

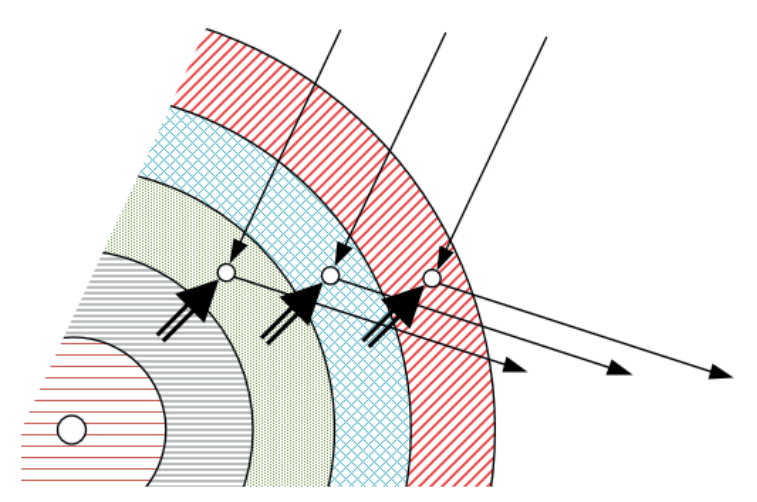

Fig. 2. A scheme for assessing a student's ability to absorb new information 
The figure schematically shows the areas of competence, and the learning process is seen as a transition from one level to another.

The figure emphasizes the following circumstance: information relating to the next level of knowledge can be learned by a student if and only if he has adequately learned the information that relates to the previous one.

Consequently, for making judgments about the level of competence of the student, user can use an approach based on reading and subsequent retelling of a text of a scientific and technical nature. As an example of such text, an article from a highly specialized journal or a technical description of a specific device can be used.

Such an approach, as will be shown below, allows the development of an artificial intelligence system that allows the assessment of the level of competence in an automated mode.

The work of the neural network underlying the proposed system, artificial intelligence, is based on the following circumstance: each level of competence is inevitably associated with a specific terminological basis. In other words, each level of competence corresponds to a specific set of keywords that can be included in the text used for testing (Figure 3).

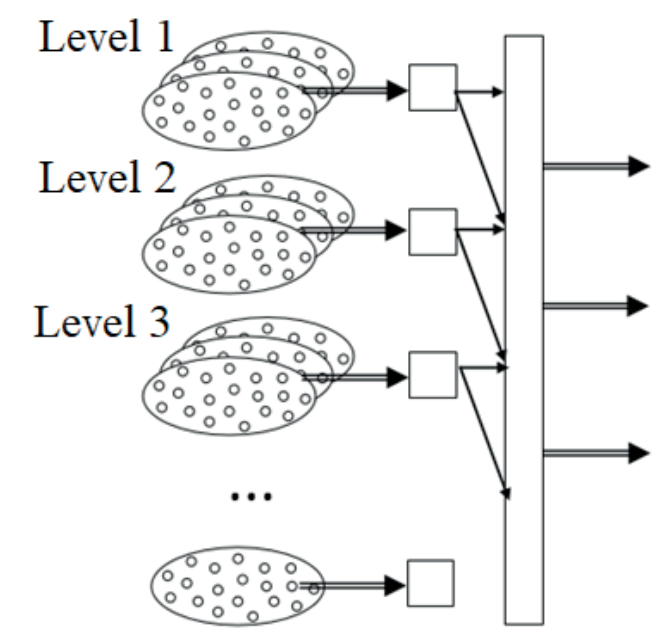

Fig. 3. Levels of competence

Keywords are divided into several groups, each of them belongs to a certain level of competence, in turn, divided into subgroups in certain areas within the same level of competence.

In the text used for testing, keywords are highlighted in color and provided with hyperlinks. If this term for the learner is unfamiliar, then he can reach by a hyperlink directly to that information resource where an explanation is contained. As such resources, publicly available sources of information are used: academic dictionaries, textbooks that are publicly available, etc.

Obviously, if the student is at the level of competence, when he is aware of the relevant groups of terms, he will not follow these links. Breaking up the links into several levels, thus allows identify the level at which the student is located, due to the fact that he goes on to higher level links.

The proposed technology involves not only tracking the links on which the student passes, in order to understand the text, but also fixing the time that he, approximately, spends on reading a thirdparty source. Obviously, the indicator can be analyzed from two points of view. More precisely, two options are possible: the material is viewed quickly or it takes quite a long time to read (obviously, if a student reads the material carefully enough, that is, he is assimilated to the student). If a student views additional material for a short time, then it either serves to recall previously known information, or it is completely incomprehensible, and the corresponding information resource will simply be closed.

Information about the links used, as well as the length of time spent on reading a third-party information resource, is stored in the program's memory, and then processed using an artificial neural network that is trained in the testing process.

For this purpose, expert assessments are also used, which are made by the teacher as a result of the retelling of this text by students.

More precisely, from a formal point of view, the assessment procedure is as follows. The student is invited to read the text on the computer screen. He explains that, for convenience, those terms that may not be known to him are already provided with hyperlinks that he can pass. Further, the student is invited to retell the text in a compressed form, on the basis of which the teacher gives an expert assessment. In this case, the student's response is recorded and processed by appropriate software. The retelling converted into text is used to work with the artificial intelligence system and its settings.

The scheme of using the proposed artificial intelligence is shown in Figure 4. This system is based on a comparison of the terms that the student used to go through the hyperlinks, as well as the terms that he 
used in the retelling. For such a comparison, an oral speech recognition system is used, which is currently quite well developed.

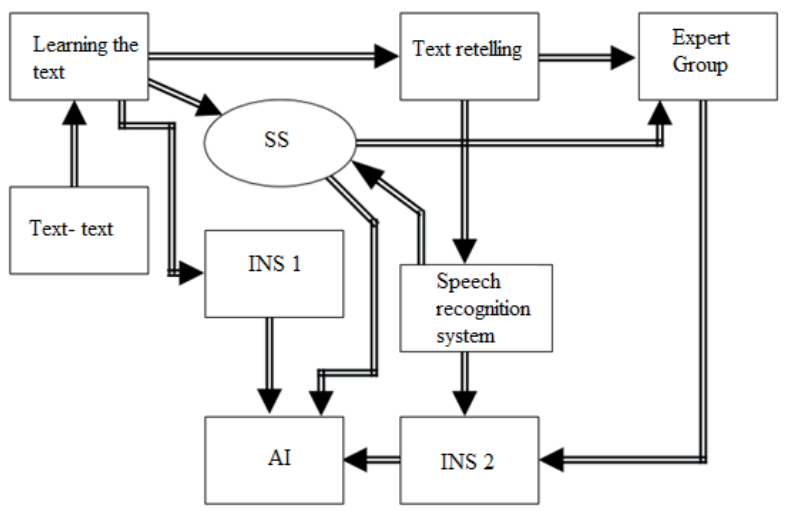

Fig. 4. Block diagram of the artificial intelligence system

Comparison of these two sets of keywords allows us to judge what terms the learner who carries out the retelling really has. (In other words, what terms he uses actively.) This principle is the basis of the diagram shown in Figure 4. The top line of diagram reflects the actions that are carried out directly during the formal exam: the learner studies the text for a specified time, then given a fixed time to retell this text, and on the basis of this retelling, the examiner gives his formal peer review.

The system conducts a quantitative comparison of the used keywords, on the basis of which a preliminary judgment is made, which the expert can use to refine his assessment. Next, the artificial intelligence system itself comes into effect, it is based on processing the results of keyword recognition in the retelling of an artificial neural network (INS 2), and the processing of those keywords that the student undergoes in the process of reading the text of an artificial neural network (INS1). The purpose of each of these neural networks in accordance with Figure 3 is to make judgments about the level of student competence.

This judgment is based on a combination of the principles of fuzzy logic with the principles of functioning of the neural network. Namely, a sequence of zeros and ones is considered as the inputs of a neural network, with each neuron of the input layer of network corresponding to a specific keyword. If a student passes a corresponding hyperlink when reading a text, then it is considered that a logical unit is supplied to the input of the corresponding neuron, if not, a logical zero.
The first layer of neural network also contains neurons that correspond to the duration of the transition time between links. Some critical threshold is set and it is considered that if the transition time between links exceeds a certain critical value, then a logical unit is supplied to the input of the corresponding element of the neural network, and if not, then a logical zero.

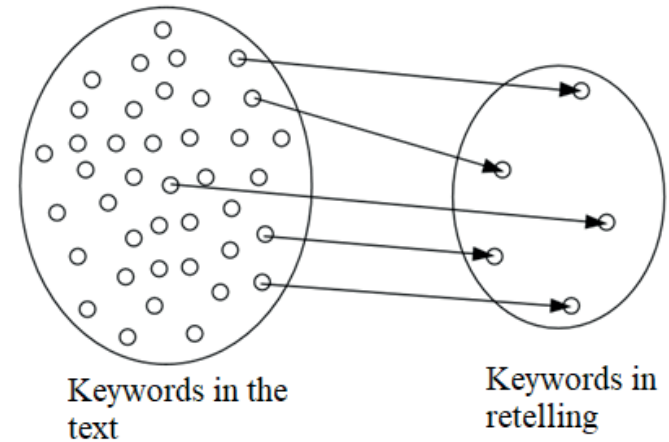

Fig. 5. To the principle of the proposed system of artificial intelligence

This approach allows, in an acceptable approximation, to estimate the time that a student spends reading materials, passing by hyperlink number $\mathrm{N}$. It is believed that if the transition time between the links with the number $\mathrm{N}$ and the number $\mathrm{N}+1$ was long enough, it means that the student spent quite a long time reading the resource associated with the reference number $\mathrm{N}$.

Such an approximate estimate is valid provided that the text is supplied with a sufficiently large number of references (determined empirically). Further, according to the standard scheme, the neural network is trained, and at its output, signals are generated corresponding to the levels of the student's competence.

Another group of inputs of neural network determines the assessment made by the teacher according to the relevant set of criteria.

The use of criteria sets corresponds to the fact that the teacher makes a comprehensive assessment, but does not give points, but converts the judgment made by him into a system of logical zeros and ones, which allows him to further process his judgments using neural network methods. The training of this system also assumes the use of foresight methods in order to eliminate subjective factors. 
We emphasize that the principle described above is based on the work as INS1, as well as INS2. In both cases we are talking about the recognition of a certain system of terms that the student used in retelling and reading the text.

Next, the results of the student's response processing by artificial neural networks are transmitted to the basic system of artificial intelligence. Its allocation as a separate module is justified for the following reasons. INS1, like INS2, are trained on a specific array of texts that are used as "exam questions". These text arrays contain certain keyword arrays, the totality of which serves as an indicator of competence.

During the exam, the student works with texts of two or more levels of difficulty (several "exam questions") according to the method described above, which allows to specify the used results. In other words, he answers two or more different questions with different levels of difficulty.

This component of the general scheme can and should be trained not only in the course of the experiment related to the retellings being made by students, but with the analysis of the source texts that provide the identification of the connection between the concepts. The revealed connections between concepts are also supposed to be used when working with INS1 and INS2. Specifically, it is assumed that the artificial intelligence system, trained in this way, gives the INS1 and INS2 the necessary information as to what kind of connections exist between the concepts; therefore, these neural networks make judgments based on the above two criteria.

We emphasize that the allocation of INS1 and INS2v separate modules due to the fact that these neural networks are trained in the course of experiments with students, and the artificial intelligence system is trained directly on the array of source data available in the open press. The corresponding relationships are shown in Figure 4, with arrows showing the presence of feedback.

\section{CONCLUSION}

Thus, there is every reason to radically reconsider approaches to assessing the level of competence of students in modern conditions. The traditional approach, based on the grading of exam grades based on the opinions of a particular teacher, has outlived its usefulness both in its methodological aspect and in that it creates fertile soil for corruption in universities.
The proposed algorithm, based on the student's ability to perceive new information of a scientific and technical nature, allows one to eliminate the basic drawbacks of the traditional approach, primarily because it is algorithmizable; on its basis, a rather simple artificial intelligence system can be implemented, ensuring that the assessment of the student's competence level is carried out automatically.

\section{REFERENCES}

[1] D. W. Chapman and S. Lindner, "Degrees of integrity: the threat of corruption in higher education," Stud. High. Educ., 2016.

[2] M. N. Kalimoldayev, I. T. Pak, S. T. Baipakbayeva, G. A. Mun, D. B. Shaltykova, and I. E. Suleimenov, "Methodological basis for the development strategy of artificial intelligence systems in the republic of kazakhstan in the message of the president of the republic of kazakhstan dated October 5, 2018," News Natl. Acad. Sci. Repub. Kazakhstan, vol. 6, no. 432, pp. 47-54, Dec. 2018.

[3] Q. Liu and Y. Peng, "Corruption in college admissions examinations in China," Int. J. Educ. Dev., 2015.

[4] A. Sabic-El-Rayess and N. N. Mansur, "Favor reciprocation theory in education: New corruption typology," Int. J. Educ. Dev., 2016.

[5] E. K. Sia, "Management and academic practices to prevent higher education corruption - a case review of an international branch campus in Uzbekistan," Tertiary Education and Management. 2014.

[6] M. J. Timms, "Letting Artificial Intelligence in Education out of the Box: Educational Cobots and Smart Classrooms," Int. J. Artif. Intell. Educ., 2016.

[7] V. Galkina, I. Khvostova, and O. Servetnik, "The use of artificial intelligence in educational automated information systems," Nauk. tekhnologii., pp. 4852, 2012.

[8] Suleymenov et al., Nekotoryye voprosy sovremennoy teorii innovatsii., vol. 197. 2016.

[9] M. Makarova and R. Vakhrushev, "Korruptsiya v vysshem obrazovanii i akademicheskaya etika," Vyss. Obraz. v Ross., 2014.

[10] A. Nosov, "Problemy informatizatsii sistemy obrazovaniya v postindustrial'nom obshchestve," Kontsept, 2015.

[11] I. Suleymenov et al., "Organizatsiya i planirovaniye nauchnykh issledovaniy / I. Suleymenov, O. Gabriyelyan, V. Buryak, N. Safonova, G. Irmukhametova, SH. Kabdushev, G. Mun,” 2018. 
[12] I. E. Suleymenov, I. T. Pak, O. A. Gabriyelyan, A. S. Bakirov, and S. N. Koldayeva, "Printsipy razrabotki kombinirovannykh sredstv obucheniye-testirovaniye," Izv. nauchno-tekhnicheskogo Obs. «kakhak», pp. 96-105, 2017.
[13] K. D. Titayev, "Pochem ekzamen dlya naroda? Etyud o korruptsii v vysshem obrazovanii," Ekon. sotsiologiya, 2005.

[14] I. Shevchenko and A. Gavrilov, "O tenevykh ekonomicheskikh otnosheniyakh $\mathrm{v}$ sfere vysshego obrazovaniya," Sotsiologicheskiye Issled., pp. 118-125, 2005. 